\title{
The Effect of the Ionosphere on Remote Sensing of Sea Surface Salinity From Space: Absorption and Emission at L Band
}

\author{
David M. Le Vine, Fellow, IEEE, and Saji Abraham, Member, IEEE
}

\begin{abstract}
The purpose of this work is to examine the effects of Faraday rotation and attenuation/emission in the ionosphere in the context of a future remote sensing system in space to measure salinity. Sea surface salinity is important for understanding ocean circulation and for modeling energy exchange with the atmosphere. A passive microwave sensor in space operating near 1.4 GHz (L-band) could provide global coverage and complement in situ arrays being planned to provide subsurface profiles. However, the salinity signal is relatively small and changes along the propagation path can be important sources of error. It is shown that errors due to the ionosphere can be as large as several psu. The dominant source of error is Faraday rotation but emission can be important.
\end{abstract}

Index Terms-Ionospheric electromagnetic propagation, microwave radiometry, ocean salinity, remote sensing.

\section{INTRODUCTION}

$\mathbf{T}$ 1 HE SALINITY of the open ocean is important for understanding ocean circulation and for modeling energy exchange with the atmosphere. For example, salinity gradients affect mixed layer processes, which influence fluxes of heat near the surface [1]. Salinity and temperature determine water density and are important factors in large-scale ocean circulation [2]. Also, changes in salinity are primarily caused by changes in freshwater (evaporation, precipitation, melting ice, or river input). These changes are manifestations of elements of the water cycle, which are poorly known over the ocean [3].

Microwave remote sensing from space could provide the necessary temporal and spatial sampling needed to understand the role of salinity in these ocean processes [2], [4]. Changes in salinity modulate the emissivity of the surface and cause changes in emission that are sufficiently strong in the low frequency portion of the microwave spectrum to be detected with passive sensors [5], [6]. Measurements from space have been proposed [7] and salinity differences were observed from space with the L- band radiometer on SKYLAB 25 [8]. Recently, experiments with L-band radiometers on aircraft have demonstrated that salinity can be retrieved with accuracy useful for studying processes in coastal regions [9], [10].

Manuscript received June 1, 2001; revised December 13, 2001.

D. M. Le Vine is with the Microwave Sensors Branch/Code 975, Laboratory for Hydrospheric Processes, Goddard Space Flight Center, Greenbelt, MD 20771 USA (e-mail: dmlevine@ priam.gsfc.nasa.gov).

S. Abraham is with the Science System and Applications, Inc., Microwave Sensors Branch/Code 975, Goddard Space Flight Center, Greenbelt, MD 20771 USA (e-mail: sabraham@synth.gsfc.nasa.gov).

Publisher Item Identifier S 0196-2892(02)04604-1.
However, measurement of sea surface salinity (SSS) in the open ocean presents a special challenge. This is so because the dynamic range of SSS in the open ocean is relatively small (about $5 \mathrm{~K}$ ) and the requirements for a scientifically useful measurement (about $0.05 \mathrm{~K}$ ) put a severe constraint on radiometric performance. A change of $0.05 \mathrm{~K}$ at L-band corresponds to a change of about 0.1 psu [7] where "psu" denotes changes measured on the practical salinity scale [11]. To put the challenge of this measurement in perspective, the dynamic range associated with changes in soil moisture is on the order of $100 \mathrm{~K}$ [12] and measurement requirements are 1-4 K [13].

Among the important potential sources of error at L-band is the ionosphere. The ionosphere causes a change in the direction of polarization (Faraday rotation) and because the ionosphere is lossy at L-band, there is both attenuation and emission along the signal path. As will be shown here, both phenomena can cause errors that are important for remote sensing of salinity at the 0.1-psu level of accuracy. A brief background is given in Appendices A and B to define Faraday rotation and attenuation in the ionosphere. In Section II, the magnitude of Faraday rotation and its effect on observed brightness temperature are presented. In Sections III-IV, attenuation and its effect on brightness temperature (emission) are discussed.

\section{FARADAY ROTATION}

\section{A. Magnitude}

The rotation of the polarization vector in the ionosphere is due to the change along the propagation path from surface to sensor of the phase, $\Omega$, in (B3). Substituting (A6) into (B4) and integrating along the propagation path, $s$, one obtains

$$
\Omega_{F}=\left(\frac{\pi}{c \nu^{2}}\right) \int \nu_{p}^{2}(s) \nu_{B}(s) \cos \left(\Theta_{B}(s)\right) \mathrm{d} s
$$

where $\Omega_{F}$ is the Faraday rotation in radians and $\Theta_{B}$ is the angle between the direction of propagation and the Earth magnetic field [14], [15]. To simplify the many calculations needed to make a global map of $\Omega_{F},(1)$ has been approximated by making the change of variables ds $=\sec (\theta) \mathrm{dz}$ where $z$ is the normal to the surface at the subsatellite point nadir and $\theta$ is the polar angle between nadir and the line of sight to the surface (incidence angle). Substituting for the plasma frequency, $\nu_{p}$ and electron gyro frequency, $\nu_{B}$, from (A2)-(A3) and replacing $B$ by its value at an altitude of $400 \mathrm{~km} \mathrm{[16],} \mathrm{one} \mathrm{obtains}$

$$
\Omega_{F} \approx 6950 B(400) \cos \left(\Theta_{B}\right) \sec (\theta) \mathrm{VTEC} .
$$



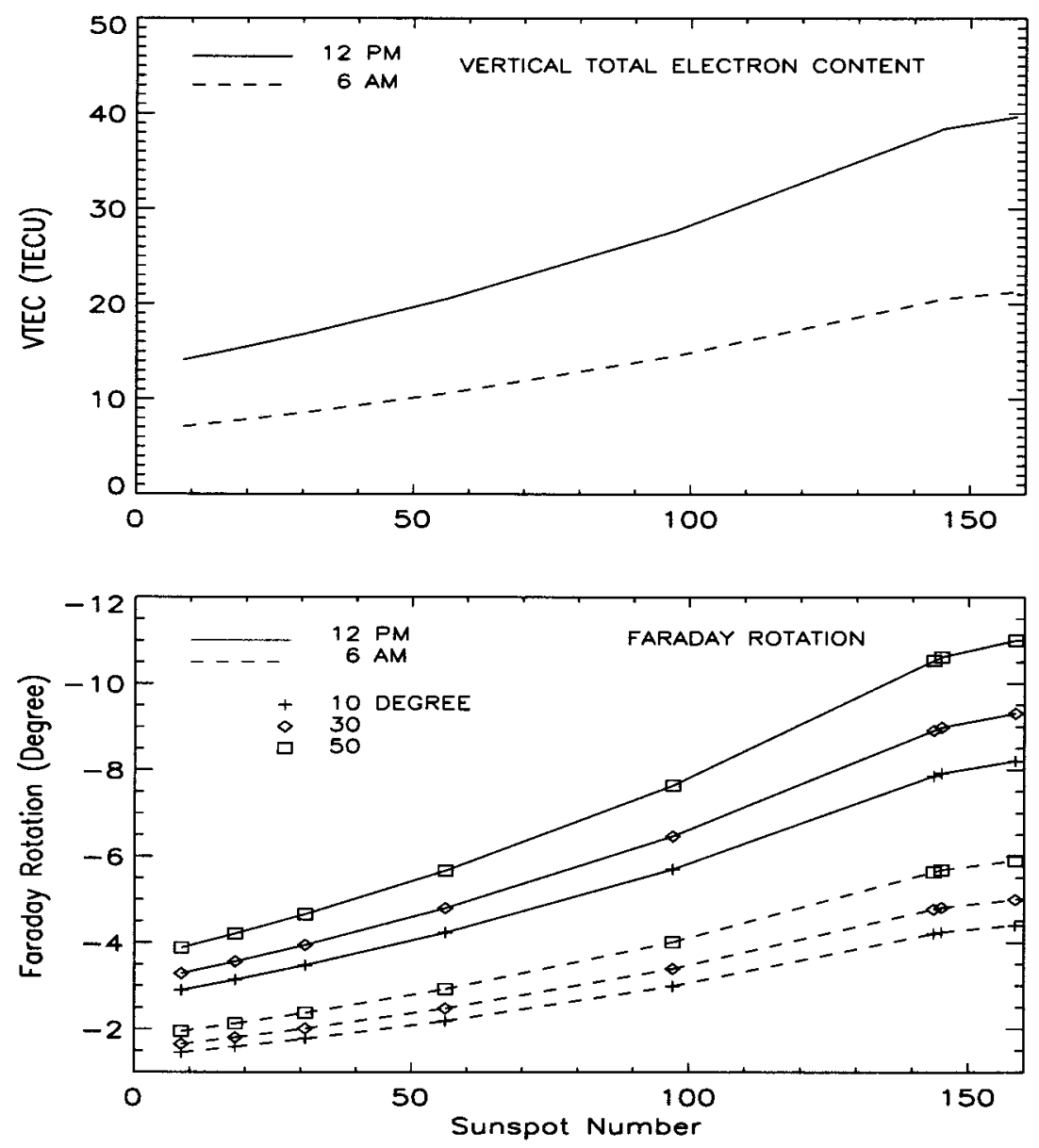

Fig. 1. Top: variation of vertical total electron content (VTEC) with solar activity. Bottom: Faraday rotation at the location 30 N, 220 E during high solar activity (June 1989). The data are for a sensor altitude of $675 \mathrm{~km}$ and looking perpendicular to the satellite heading to the right. The solid and dashed lines are for local time noon and 6 am, respectively.

These approximations are reasonable because $B$ is slowly varying with altitude and because there is little curvature of the ray path. In (2), $B$ is in tesla, $\Omega_{F}$ is in degrees, and VTEC $=\int N_{e}(z) \mathrm{dz}$ is the vertical total electron content at the sub-satellite point in total electron content units $\left(10^{16}\right.$ electrons $\left./ \mathrm{m}^{2}\right)$.

It is clear from (1) and (2) that Faraday rotation depends on electron density and magnetic field and also on the orientation of the sensor with respect to the local magnetic field (i.e., on $\Theta_{B}$ ). Examples of the effect of sensor orientation (scan pattern and look angle) can be found in [16]. For purposes of this paper, it will be assumed that the sensor looks to the right (i.e., across track in the plane perpendicular to the satellite heading). The sensor will be assumed to be in a sun-synchronous orbit with an altitude of $675 \mathrm{~km}$, which is representative of orbits proposed for microwave remote sensing at L-band [4]. Faraday rotation will be computed using the International Reference Ionosphere (IRI-95) [17] to generate the necessary electron density profiles and the International Geomagnetic Reference Field (IGRF) [18] for the magnetic field.

Fig. 1 shows the Faraday rotation at a fixed location (30 N, 220 E) over the Pacific Ocean just off the coast of North America. The top panel shows VTEC at this location as a function of solar activity given in terms of the sunspot number
Rz. (Rz is a 12-month, running mean centered on the middle of the month of interest.) The data are for June and the solid line is for a local time of noon and the dashed line for $6 \mathrm{am}$. The lower panel shows Faraday rotation at this location for several incidence angles, $\theta$. This example illustrates some general characteristics: VTEC increases with solar zenith angle and solar activity, and for a fixed sensor orientation Faraday rotation increases with VTEC and incidence angle. Faraday rotation varies as $\cos \left(\Theta_{B}\right)[\sec (\theta)$ VTEC]; hence, orientation of the sensor with respect to the magnetic field affects the rate of change with incidence angle and VTEC.

Fig. 2 shows the global distribution of Faraday rotation for a sensor with the orientation and altitude given above. The data are for a local time of $6 \mathrm{am}$ (left) and noon (right) for incidence angles of 20,30, 40, and 50 degrees. These data are for June, 1989, a very active Sun near solar maximum with sunspot number, $\mathrm{Rz}=$ 158. Notice the north-south bias in these maps, reflecting that the computation is for summer in the northern hemisphere. Also notice the east-west symmetry, which reflects that the computation is for constant local time ( 6 am or noon). However, there are significant deviations from these simple generalizations. For example, notice at noon (right) the peaks in Faraday rotation south of Australia and also over northern Asia. These patterns reflect the complex variations of VTEC with latitude and longitude and 

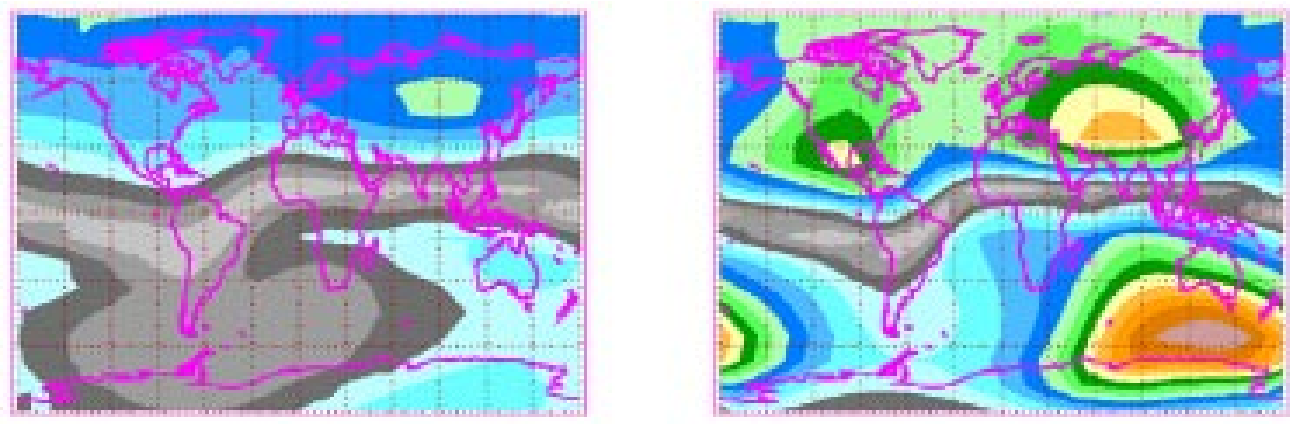

\section{Degree}
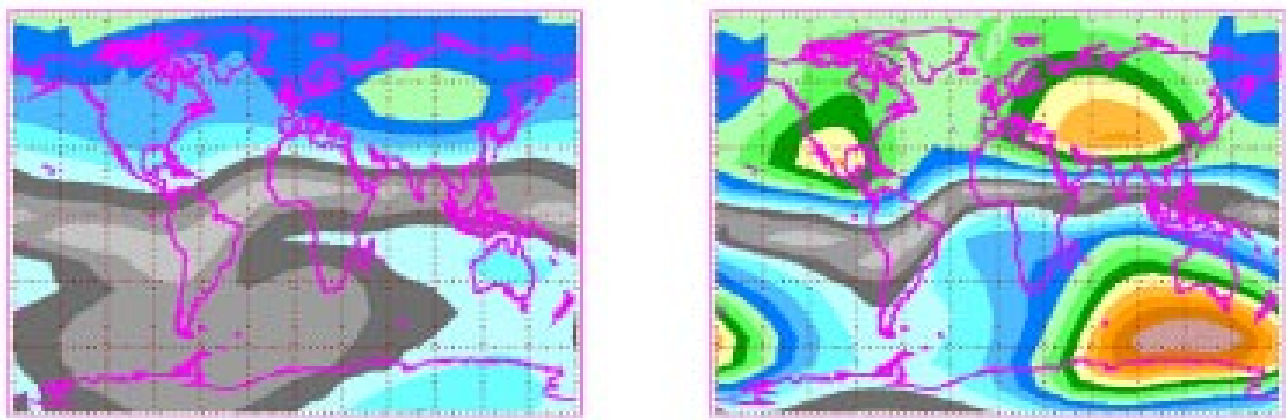

\section{Degree}
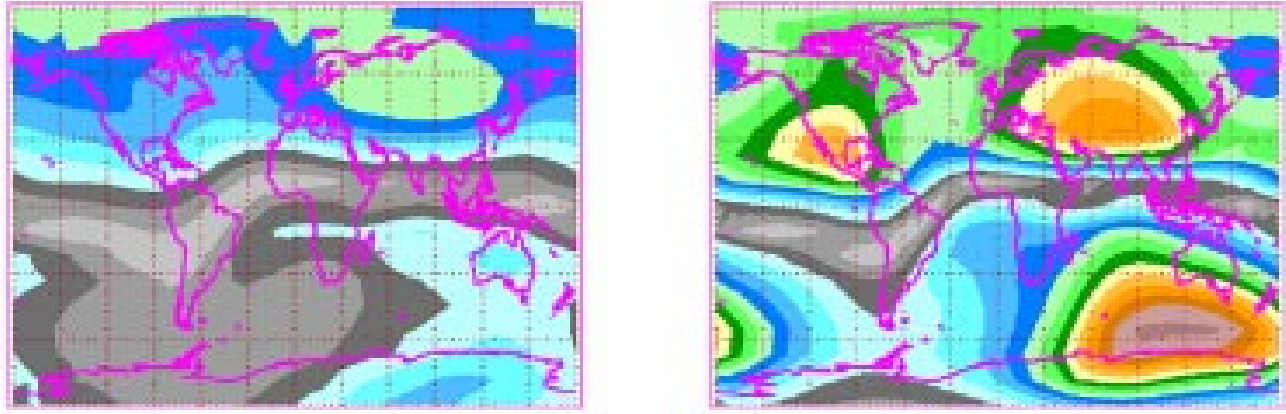

\section{Degree}
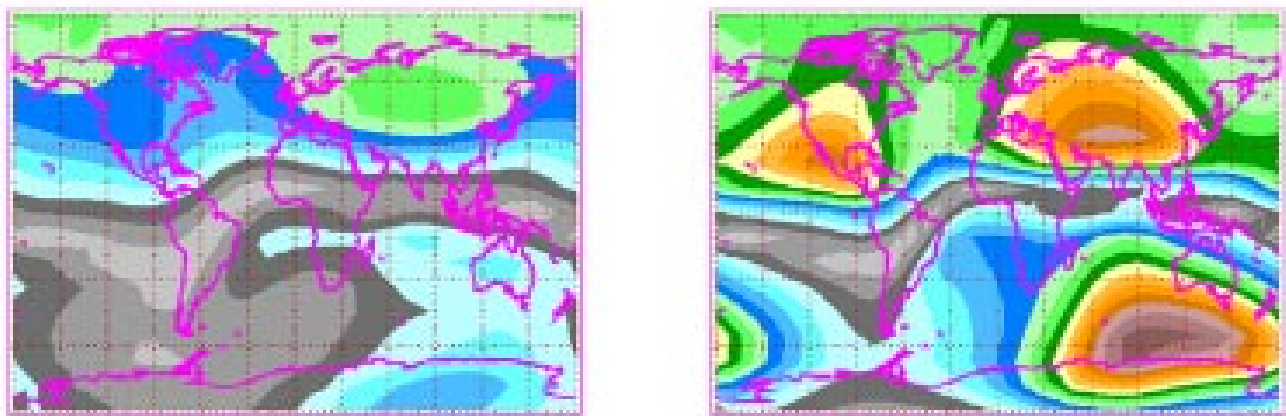

\section{Degree}

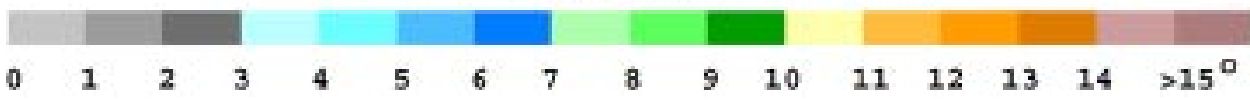

Fig. 2. Global distribution of Faraday rotation for local time of 6 am (left) and noon (right). The data are for high solar activity (June 1989), an altitude of 675 km, and looking perpendicular to the satellite heading to the right at incidence angles as indicated (20, 30, 40, and 50 degrees).

the dependence of Faraday rotation on orientation with respect to the local magnetic field (i.e., $\Theta_{B}$ ). Additional examples illus- trating the dependence on solar activity, local time and sensor orientation can be found in [16] and [19]. 

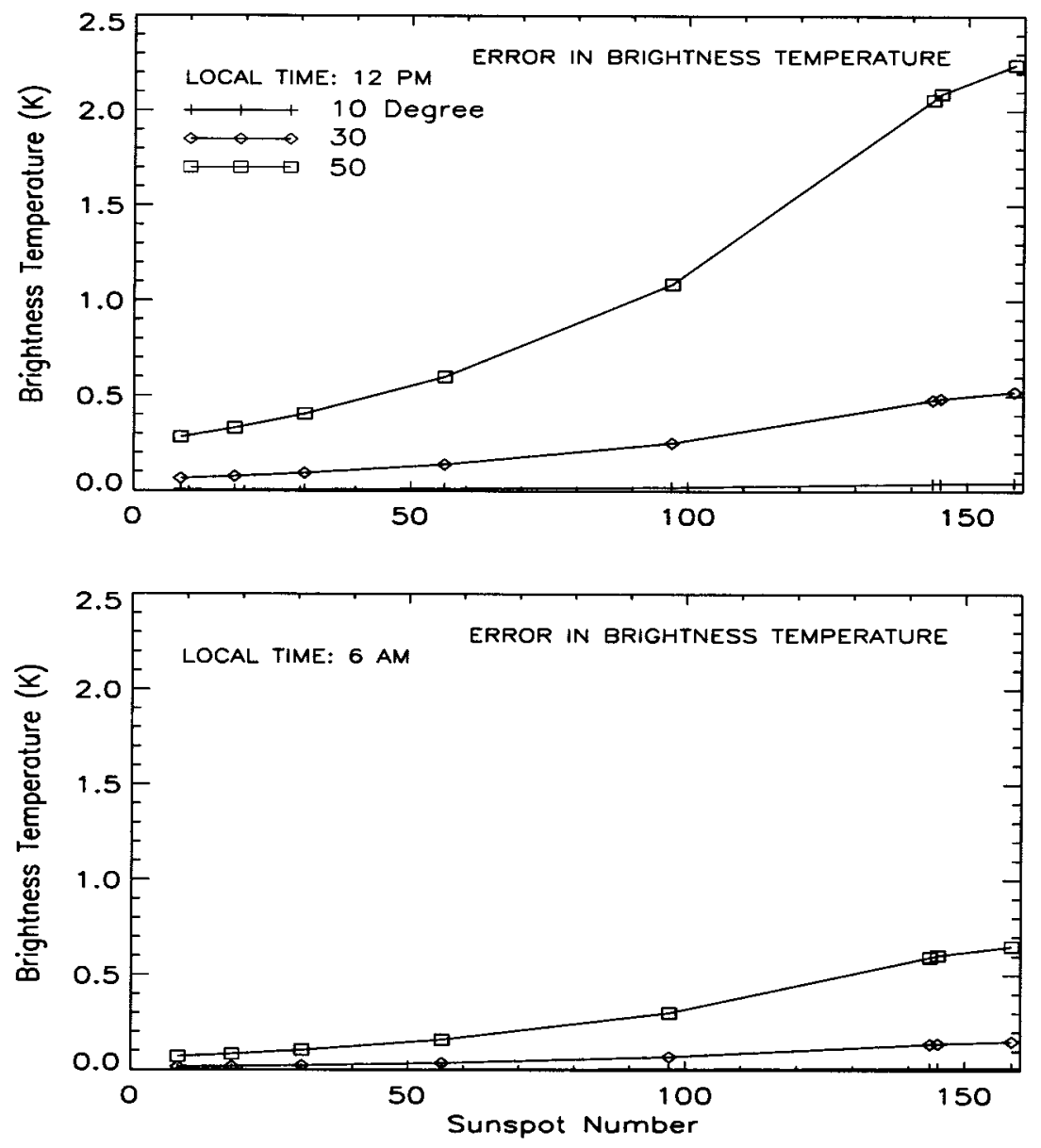

Fig. 3. Error in brightness temperature due to neglecting Faraday rotation at noon (top) and 6 am (bottom) at $30 \mathrm{~N}, 220 \mathrm{E}$ for high solar activity (June 1989). The data are for a sensor at altitude of $675 \mathrm{~km}$ and looking perpendicular to the satellite heading to the right. The surface is ocean with $S=35 \mathrm{psu}$ and $T_{0}=20 \mathrm{C}$.

\section{B. Effect on Brightness Temperature}

Faraday rotation is a potential source of error for remote sensing because radiation of given polarization at the surface will have mixed polarization when it arrives at the sensor. In particular, given the physical temperature of the surface $T_{o}$ and the emissivity $e_{h, v}$ for horizontal and vertical polarization, respectively, one obtains the following expression for the brightness temperatures, $T_{h, v}\left(\Omega_{F}\right)$, at the sensor:

$$
\begin{aligned}
& T_{h}\left(\Omega_{F}\right)=\left[e_{h} \cos ^{2}\left(\Omega_{F}\right)+e_{v} \sin ^{2}\left(\Omega_{F}\right)\right] T_{o} \\
& T_{v}\left(\Omega_{F}\right)=\left[e_{v} \cos ^{2}\left(\Omega_{F}\right)+e_{h} \sin ^{2}\left(\Omega_{F}\right)\right] T_{o} .
\end{aligned}
$$

Inverting (3) without correcting for Faraday rotation $\Omega_{F}$ can result in error because $e_{v}$ and $e_{h}$ are different functions of salinity [6].

For purposes of deciding when the error might be significant, it is convenient to examine the change in brightness temperature, $\Delta T\left(\Omega_{F}\right)=T\left(\Omega_{F}\right)-T(0)$, due to Faraday rotation. From (3), one obtains

$$
\Delta T_{h, v}\left(\Omega_{F}\right)= \pm\left[e_{v}-e_{h}\right] \sin ^{2}\left(\Omega_{F}\right) T_{o}
$$

where the "+" and "-"signs are for $\mathrm{H}$ - and V-polarization, respectively. To compute $\Delta T$, it has been assumed that the surface is flat and without roughness (waves or foam). In this case, the emissivity is

$$
e_{h, v}=1-\left|R_{h, v}(\theta)\right|^{2}
$$

where $R_{h, v}(\theta)$ are the Fresnel reflection coefficients

$$
\begin{aligned}
& R_{v}(\theta)=\frac{\epsilon_{r} \cos (\theta)-\left\{\epsilon_{r}-\sin ^{2}(\theta)\right\}^{1 / 2}}{\epsilon_{r} \cos (\theta)+\left\{\epsilon_{r}-\sin ^{2}(\theta)\right\}^{1 / 2}} \\
& R_{h}(\theta)=\frac{\cos (\theta)-\left\{\epsilon_{r}-\sin ^{2}(\theta)\right\}^{1 / 2}}{\cos \theta+\left\{\epsilon_{r}-\sin ^{2}(\theta)\right\}^{1 / 2}}
\end{aligned}
$$

and $\epsilon_{r}$ is the relative dielectric constant of sea water and is a function of salinity and temperature. The relationship for L-band reported by [6] has been used here.

Fig. 3 shows $\Delta T_{h}\left(\Omega_{F}\right)$ as a function of solar activity at the fixed location ( $30 \mathrm{~N}, 220 \mathrm{E})$. The top panel is for local time of noon and the bottom panel is for $6 \mathrm{am}$. The data are for the month of June, a sensor at $675 \mathrm{~km}$ altitude, and looking to the right with incidence angles of 10,30, and 50 degrees. The Faraday rotation and VTEC are given in Fig. 1. The calculations were made for 

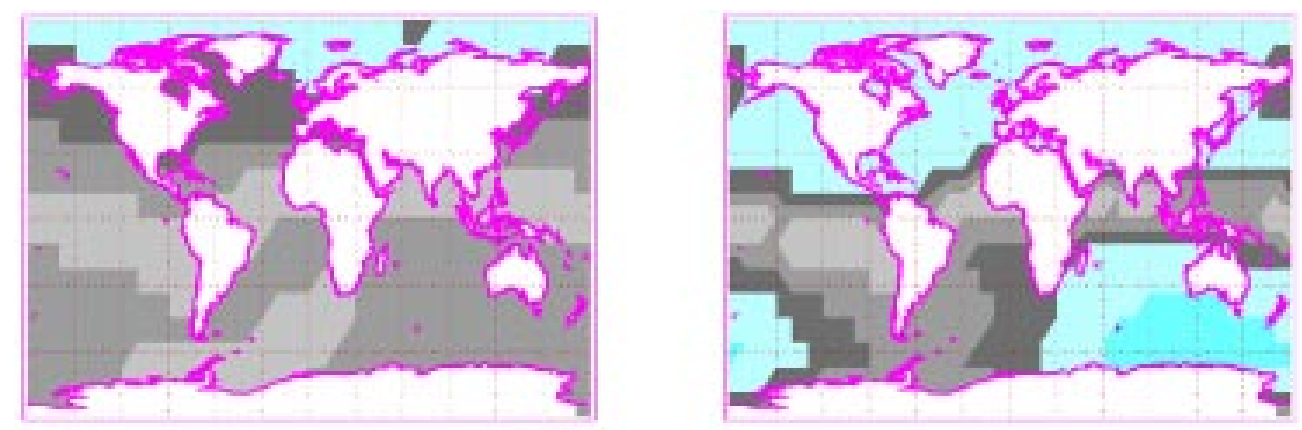

\section{Degree}
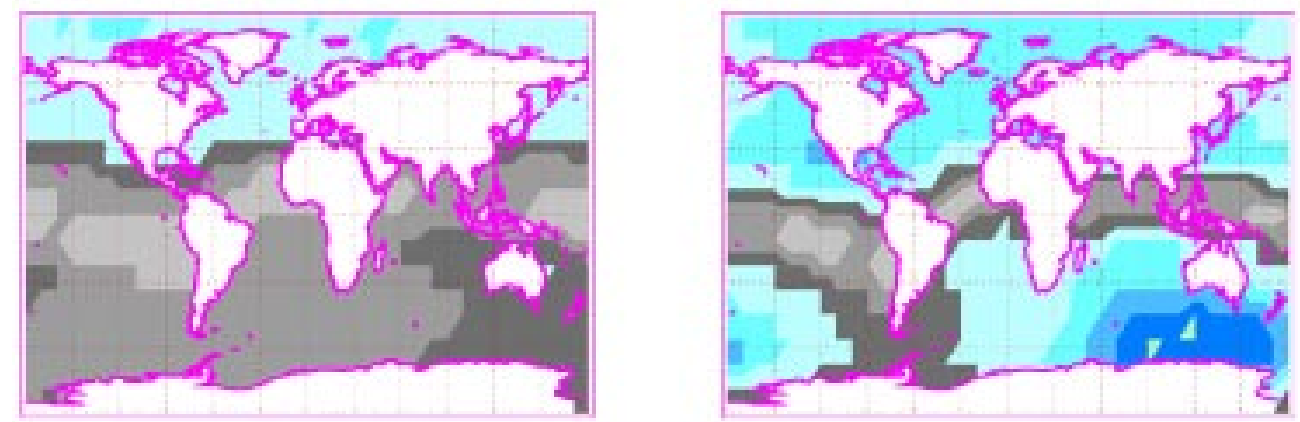

\section{Degree}
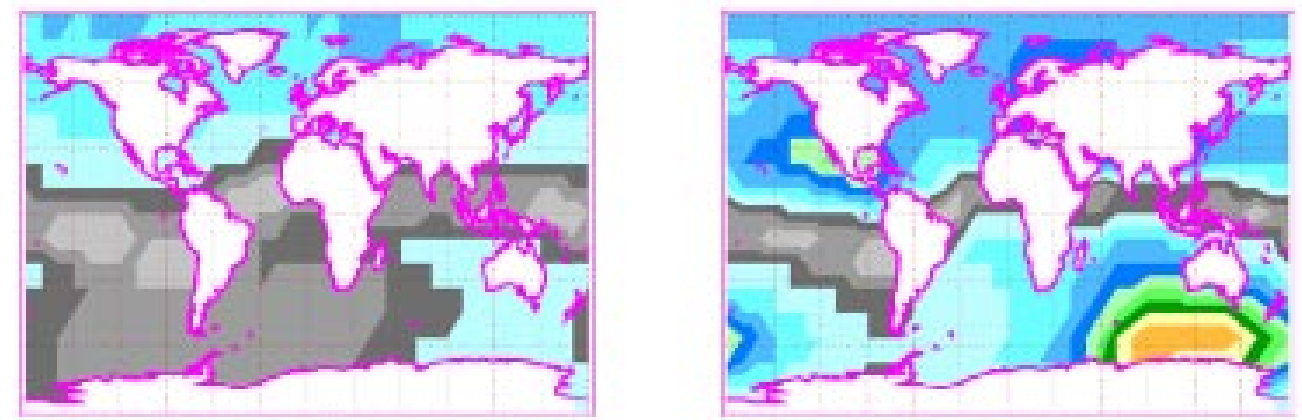

\section{Degree}
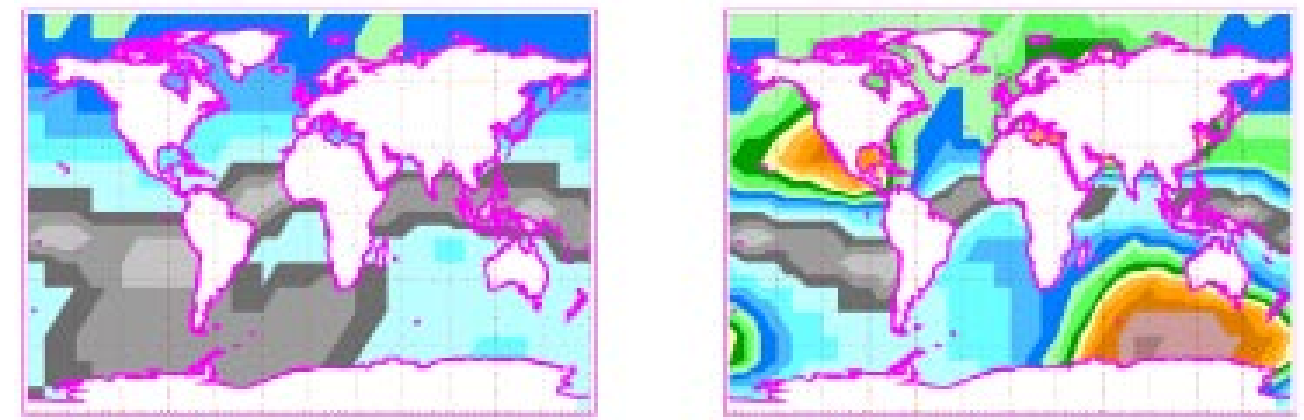

\section{Degree}

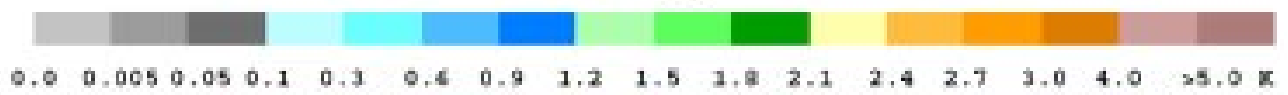

Fig. 4. The global distribution of the error in brightness temperature as a function of incidence angle due to neglecting Faraday rotation at 6 am (left) and noon (right). The data are for high solar activity (June 1989; Rz $=158$ ) and for a sensor at altitude of $675 \mathrm{~km}$ and looking perpendicular to the satellite heading to the right. The surface is ocean with $S=35$ psu and $T_{0}=20 \mathrm{C}$.

an ocean surface with $S=35 \mathrm{psu}$ and $T_{o}=20 \mathrm{C}$. Notice that the error incurred by ignoring Faraday rotation increases with incidence angle and solar activity as one would expect (because Faraday rotation increases with these parameters) and the error 

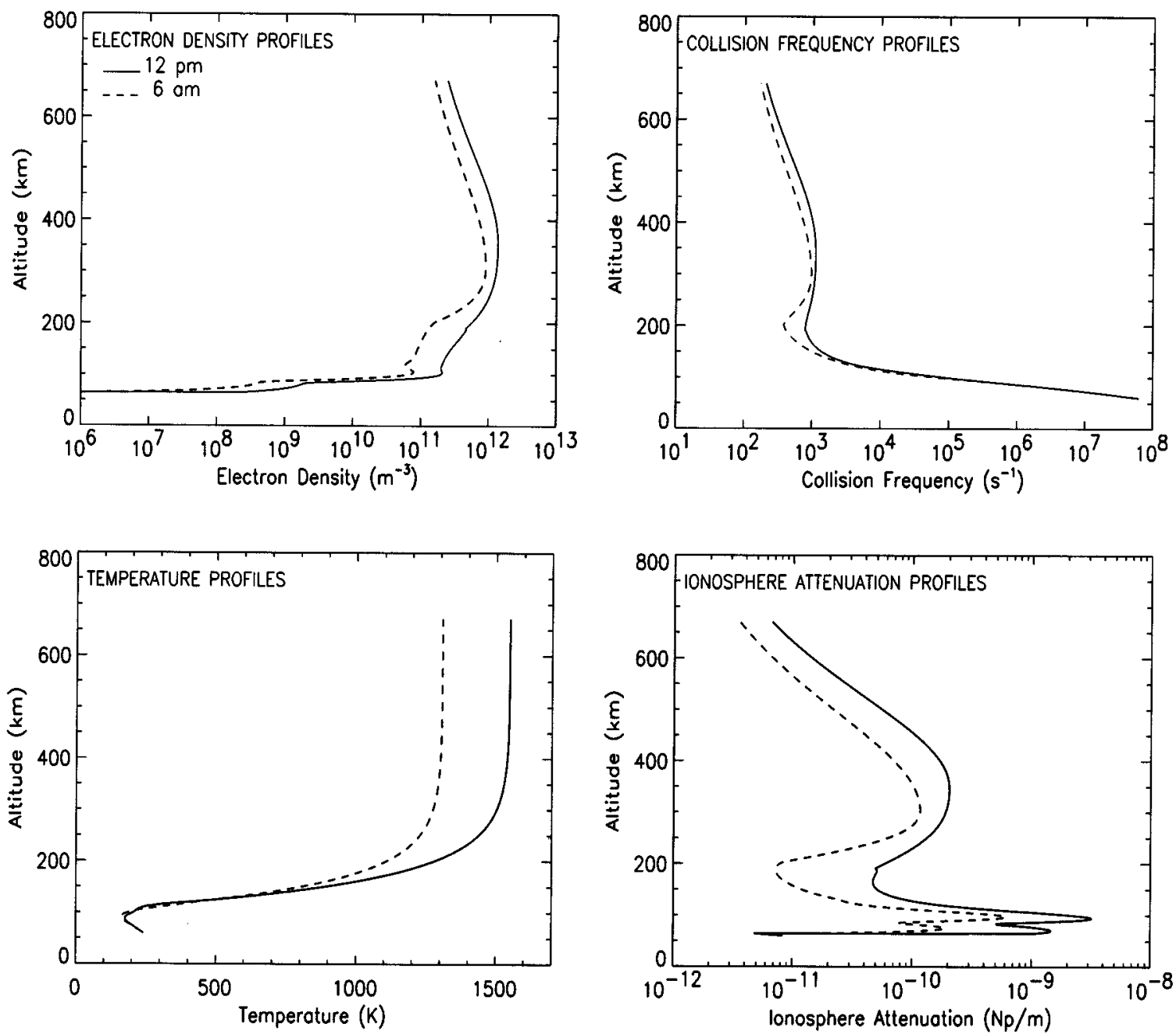

Fig. 5. Profiles of ionosphere parameters (electron density, collision frequency, temperature, and attenuation) at $30 \mathrm{~N}, 330 \mathrm{E}$ for local times of noon (solid) and 6 am (dashed) and high solar activity (June 1989).

is much worse at noon than at 6 am. For incidence angles less than 40 degrees, the error at 6 am is less than $0.3 \mathrm{~K}$ even at maximum solar activity. At noon, the error is much larger (Fig. 3, top panel).

Fig. 4 shows the global distribution of brightness temperature error, $\Delta T_{h}\left(\Omega_{F}\right)$, over the oceans. These calculations were made for an ocean surface with $S=35 \mathrm{psu}, T_{o}=20 \mathrm{C}$ and for a period of solar maximum (June 1989). The panel on the left is for a local time of $6 \mathrm{am}$ and on the right for noon. Notice that, at $6 \mathrm{am}$, mid-latitudes and moderate incidence angles the error in brightness temperature is less than $0.3 \mathrm{~K}$. However, much larger values are possible at local noon, even at moderate incidence angles. (To approximate the error in the estimate of salinity, the ratio $0.5 \mathrm{~K} / \mathrm{psu}$ is useful.)

\section{IONOSPHERE ABSORPTION}

\section{A. Magnitude of Absorption}

As shown in Appendix B, the dominant loss due to absorption in the ionosphere is determined by the coefficient $\beta$ [cf. (B3) and (B4)]. As will be shown below, the term $\delta$ (attenuation due to ellipticity) in (B3) is very much smaller at L-band and can be neglected. Neglecting terms of the order $\nu_{p}^{2} / \nu^{2}$ compared to unity in (A6) and (B4), one obtains

$$
\begin{aligned}
\beta & =\frac{1}{2 c} \frac{\nu_{p}^{2} \nu_{z}}{\nu^{2}} \\
& \approx 40.5 \frac{N_{e} \nu_{z}}{c \nu^{2}} .
\end{aligned}
$$

In order to compute $\beta$, both the electron density $N_{e}$ and the collision frequency $\nu_{z}$ are needed. To estimate the collision frequency, we use the "effective" collision frequency defined by [20]

$$
\nu_{\mathrm{eff}}=\nu_{\mathrm{ei}}+\nu_{\mathrm{en}}+\nu_{\mathrm{in}}
$$

where

$$
\begin{aligned}
& \nu_{\text {ei }}=\left[34+4.18 \log _{10}\left(\frac{T^{3}}{N_{e}}\right)\right] N_{e} T^{-3 / 2} \\
& \nu_{\text {en }}=5.4 \times 10^{-10} N_{n} T^{1 / 2} \\
& \nu_{\text {in }}=2.6 \times 10^{-9}\left(N_{e}+N_{n}\right) W^{-1 / 2} .
\end{aligned}
$$

In these expressions, the subscripts $e, i$, and $n$ denote electrons, ions, and neutral particles, respectively. $W$ is the molecular weight of ions and neutral particles (assumed equal) and $T$ 
TABLE I

INTEGRATED PARAMETERS (NADIR AND LOCATION: 30 N, 330 E)

\begin{tabular}{|c|c|c|c|c|}
\hline \multirow{3}{*}{$\begin{array}{l}\text { Ionospheric } \\
\text { parameters }\end{array}$} & \multicolumn{2}{|c|}{ HSA } & \multicolumn{2}{|c|}{ LSA } \\
\hline & \multicolumn{2}{|c|}{ LOCAL TIME } & \multicolumn{2}{|c|}{ LOCAL TIME } \\
\hline & Noon & $6 \mathrm{AM}$ & Noon & $6 \mathrm{AM}$ \\
\hline $\begin{array}{c}\operatorname{VTEC}(\text { TECU) } \\
\int_{N} \text { dh }\end{array}$ & 43.5 & 24.9 & 13.8 & 7.11 \\
\hline $\begin{array}{c}\text { Faraday Rotation } \\
\text { (degrees) } \\
\int \Omega \mathrm{dh}\end{array}$ & 7.31 & 4.17 & 2.24 & 1.15 \\
\hline $\begin{array}{l}\text { Ellipticity (neper) } \\
\int \delta \mathrm{dh}\end{array}$ & $5.99 \times 10^{-13}$ & $1.61 \times 10^{-13}$ & $7.79 \times 10^{-14}$ & $1.34 \times 10^{-14}$ \\
\hline $\begin{array}{l}\text { Optical Depth (neper) } \\
\qquad=2 \int \beta \text { dh }\end{array}$ & $12.37 \times 10^{-5}$ & $3.51 \times 10^{-5}$ & $5.03 \times 10^{-5}$ & $1.57 \times 10^{-5}$ \\
\hline $\begin{array}{c}\text { Change in } T_{B}(m K) \\
\Delta T_{B}\end{array}$ & 10.20 & 2.89 & 4.15 & 1.30 \\
\hline
\end{tabular}

Integrated Ionospheric parameters during High Solar Activity (HSA) and Low Solar Activity (LSA) at the location (30N, 330E). The ocean surface has salinity $(S)=35$ psu and surface temperature $\left(T_{0}\right)=20^{\circ} \mathrm{C}$. The computation is for JUNE and local time of $6 \mathrm{AM}$ and Noon. The integration is done at nadir. One TECU $=10^{16}$ electrons $/ \mathrm{m}^{2}$.

is the temperature of all constituents. The concentrations $N$ are in units of $\mathrm{cm}^{-3}$ and the collision frequencies are in $\mathrm{Hz}$.

Computations of $\beta$ have been made here using the IRI-95 [17] to obtain electron density profiles and using the MassSpectrometer-Incoherent-Scatter (MSIS) model [21] to generate the profiles of temperature and neutral particle density ( $T$ and $N_{n}$ ) needed in (10). Values of $\beta$ were computed as a function of altitude in steps of $1 \mathrm{~km}$ and then integrated along the ray path to obtain an optical depth: $\tau=2 \int \beta(z) \mathrm{dz}$. The optical depth gives the attenuation of power (i.e., brightness temperature).

Fig. 5, shows vertical profiles at (30 N, 330 E). Profiles are shown for electron density $N_{e}$, collision frequency $\nu_{\mathrm{eff}}$, temperature $T$, and attenuation coefficient $\beta$ for local times of 6 am (dashed) and noon (solid). The calculations are for a period of high solar activity (June 1989). Notice the peak in the profile of attenuation coefficient at low altitude (near $100 \mathrm{~km}$ ). This occurs because the collision frequency increases rapidly in low altitudes. Hence, even though the electron density has decreased substantially from its peak near $300 \mathrm{~km}$ (F-region), attenuation is not negligibly small in the lower ionosphere. Integrated values of these parameters are shown in Table I. The table shows values for high and also low solar activity. Values for Faraday rotation $\Omega_{F}$ and the ellipticity factor $\delta$ are included for reference. Notice how much smaller $\delta$ is than $\beta$. All of the integrated values are for an altitude of $675 \mathrm{~km}$ and a vertical path. The values scale roughly as $\sec (\theta)$ for incidence angles less than 50 degrees.

\section{B. Loss of Brightness Temperature}

The signal emitted from the surface is $T_{h, v}=e_{h, v}(\theta) T_{o}$ and it is attenuated as it propagates through the ionosphere to the sensor. For purposes of estimating the effect of this attenuation, define the loss in brightness temperature to be the difference between the temperature that actually arrives at the sensor and the signal that would arrive in the absence of attenuation (and Faraday rotation). Calling this difference $\Delta T_{B}$, one obtains

$$
\Delta T_{B}(\theta)=e_{h, v}(\theta) T_{o}[1-\exp (-\tau \sec (\theta))] .
$$

Since $\tau$ is small, this is approximately

$$
\Delta T_{B}(\theta)=e_{h, v}(\theta) T_{o}[\tau \sec (\theta)] .
$$

Values of $\Delta T_{B}$ at (30 N, $330 \mathrm{E}$ ) are given in Table I. These values are for nadir (vertical and horizontal polarization are equal) and it is obvious from (11) that the attenuation increases with incidence angle approximately as $\sec (\theta)$. The values given in Table I assume a water surface with a salinity of 35 psu and temperature of $20{ }^{\circ} \mathrm{C}$. Values at selected locations around the globe (shown in Fig. 6) are given in Table II for a local time of 6 am and in Table III for a local time of noon. The same values of salinity and temperature are used at each location (35 psu and $20^{\circ} \mathrm{C}$ ). The only variations are with parameters of the ionosphere. Notice that, at nadir, in the case of high solar activity and noon, it is possible to have a loss of $0.01 \mathrm{~K}$. However, the loss is much less at $6 \mathrm{am}$, even at high solar activity.

\section{IONOSPHERE EMISSION}

Loss in the ionosphere also means that there will be emission (additional signal which is not related to surface properties). There are two components of this emission, a signal emitted upward toward the radiometer from the column of ionosphere between the sensor and surface and signal emitted downward that is reflected at the surface into the sensor's field-of-view. Using a conventional radiative transfer model for a uniform layer, one can write these terms as follows [7], [22]:

$$
T_{B}=\left[T_{\text {surf }}+\left(1-e_{h, v}(\theta)\right) T_{\downarrow}\right] \exp \{-\tau(h) \sec (\theta)\}+T_{\uparrow}
$$




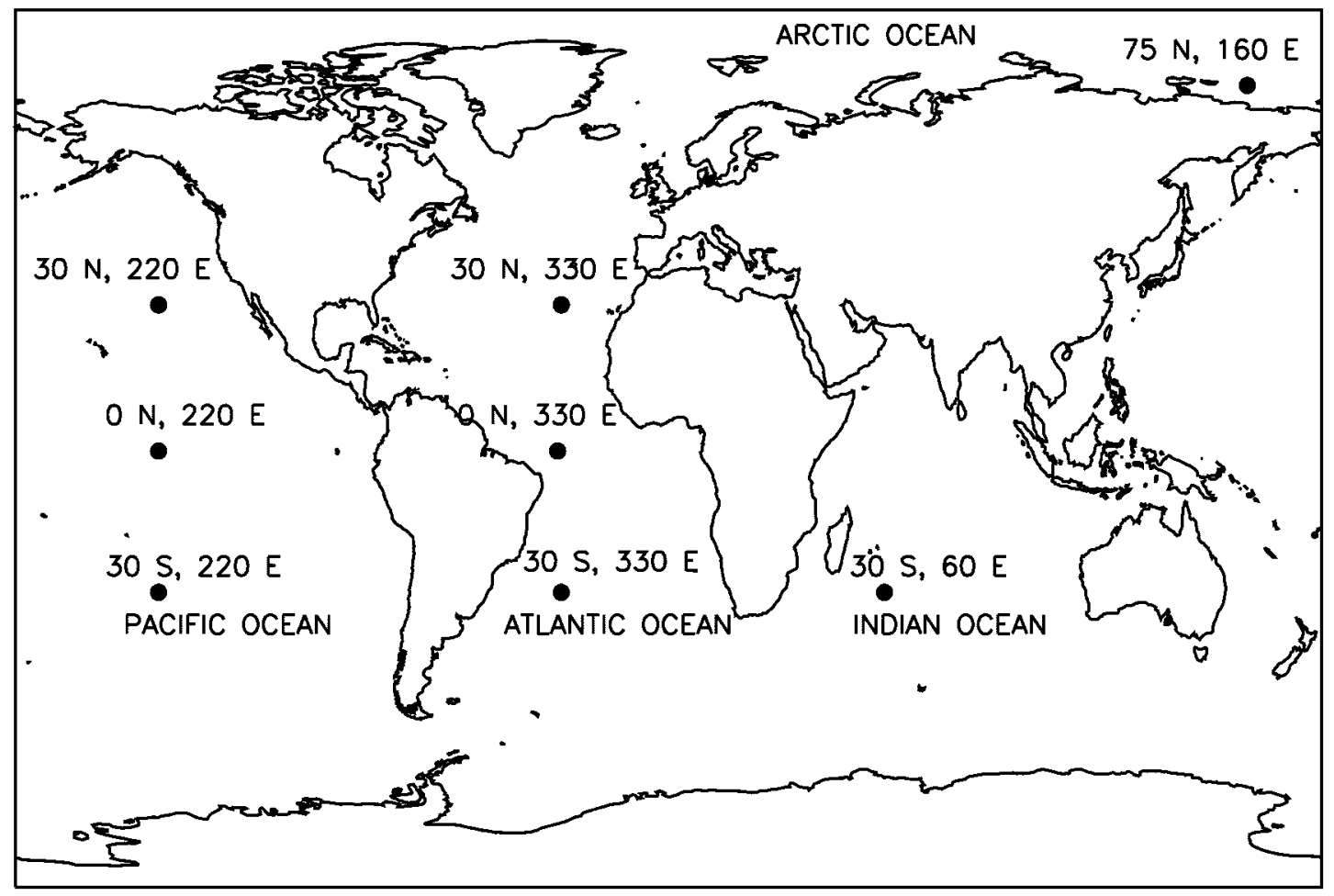

Fig. 6. Location where the calculation of ionospheric absorption and emission were made.

where

$$
\begin{aligned}
& T_{\text {surf }}= e_{h, v}(\theta) T_{o} \\
& T_{\uparrow}=\sec (\theta) \int_{0}^{h} T_{\mathrm{ion}}(z) \bar{\beta}(z) \\
& \cdot \exp \left\{-\sec (\theta) \int_{z}^{h} \bar{\beta}(x) \mathrm{dx}\right\} \mathrm{dz} \\
& T_{\downarrow}=\sec (\theta) \int_{0}^{\infty} T_{\mathrm{ion}}(z) \bar{\beta}(z) \\
& \cdot \exp \left\{-\sec (\theta) \int_{0}^{z} \bar{\beta}(x) \mathrm{dx}\right\} \mathrm{dz} .
\end{aligned}
$$

In these expressions, (13a) is the nominal emission from the surface, $h$ is the altitude of the sensor $(675 \mathrm{~km}$ in the numerical examples), $\bar{\beta}(z)=2 \beta(z)$ is the attenuation coefficient for power at altitude $z$ as given by (7), $e_{h, v}(\theta)$ is the emissivity of the surface and $R_{h, v}(\theta)$ is the Fresnel reflection coefficient of the surface as defined by (6), and $T_{\text {ion }}$ is the temperature of the ionosphere and $T_{o}$ is the temperature of the surface. $T_{\uparrow}$ is the signal emitted by the ionosphere along the line-of-sight between the surface and sensor. This term is due to thermal emission and is the same for both polarizations. $T_{\downarrow}$ is the radiation emitted by the entire column of ionosphere downward to the surface. This radiation is reflected at the surface and then attenuated as it propagates from the surface toward the sensor. The net contribution is $\left(1-e_{h, v}(\theta)\right) T_{\downarrow} \exp \{-\tau(h) \sec (\theta)\}$ as given in (12). This term is polarization-dependent because reflection at the surface depends on polarization.

Examples of the upwelling and downwelling terms in (12) are given at a fixed location $(30 \mathrm{~N}, 330 \mathrm{E})$ in Fig. 7. The radiation is shown for nadir and an incidence angle of 50 degrees as a function of local time. The data are for a period of high solar activity (June 1989) and assume a surface with salinity of $35 \mathrm{psu}$ and temperature of $20 \mathrm{C}$ and a sensor at $675 \mathrm{~km}$. The upwelling radiation (top) is unpolarized. The downwelling radiation is the net term, $\left(1-e_{h, v}(\theta)\right) T_{\downarrow} \exp \{-\tau(h) \sec (\theta)\}$, in (12). This term is different for vertical polarization (middle) and horizontal polarization (bottom) because $e_{h, v}(\theta)$ is different for the two polarizations.

Tables II and III list examples for the several locations around the globe shown in Fig. 6. The data are for the month of June and for high and low solar activity $(\mathrm{Rz}=158.4$ and 8.5) corresponding to solar maximum and minimum, respectively. The data in Table II are for local time of 6 am and the data in Table III are for noon. Values are presented for optical depth $\tau$, for the loss in brightness temperature due to attenuation $\Delta T$, and for the upwelling radiation $T_{\uparrow}$ and downwelling radiation $T_{\downarrow}$. The results are for nadir (vertical and horizontal polarization are the same). Notice that the total radiation at the sensor (upwelling plus downwelling) ranges from 0.001 to $0.055 \mathrm{~K}$ at 6 am depending on location and solar activity. To put this in perspective, the salinity signal is approximately $0.5 \mathrm{~K} / \mathrm{psu}$. Thus, a change of $0.05 \mathrm{~K}$ is an error of about $0.1 \mathrm{psu}$. This is important for monitoring salinity in the open ocean but probably not important for applications in the coastal ocean [23]. 
TABLE II

IONOSPHERIC ATTENUATION AND EMISSION (6 AM)

\begin{tabular}{|c|c|c|c|c|c|c|c|}
\hline \multicolumn{2}{|c|}{ Location } & \multirow[t]{2}{*}{$\mathbf{R z}$} & \multirow{2}{*}{$\begin{array}{c}\text { VTEC } \\
\text { (TECU) }\end{array}$} & \multirow{2}{*}{$\begin{array}{c}\tau \\
\left(10^{-5} \text { Neper }\right)\end{array}$} & \multirow{2}{*}{$\begin{array}{c}\Delta \mathrm{T} \\
(\mathrm{mK})\end{array}$} & \multirow{2}{*}{$\begin{array}{c}\mathrm{T}_{\uparrow} \\
(\mathbf{m K})\end{array}$} & \multirow{2}{*}{$\begin{array}{c}\mathbf{T}_{\downarrow} \\
(\mathbf{m K})\end{array}$} \\
\hline Latitude & Longitude & & & & & & \\
\hline \multirow[t]{2}{*}{$30 \mathrm{~N}$} & \multirow[t]{2}{*}{$220 \mathrm{E}$} & 158.4 & 19.9 & 2.64 & 2.18 & 20.87 & 16.08 \\
\hline & & 8.5 & 6.4 & 1.45 & 1.20 & 4.75 & 3.51 \\
\hline \multirow[t]{2}{*}{$\mathbf{0}$} & \multirow[t]{2}{*}{$220 \mathrm{E}$} & 158.4 & 20.6 & 2.47 & 2.04 & 23.01 & 18.22 \\
\hline & & 8.5 & 8.6 & 1.19 & 0.98 & 5.31 & 5.06 \\
\hline \multirow[t]{2}{*}{$30 \mathrm{~S}$} & \multirow[t]{2}{*}{$220 \mathrm{E}$} & 158.4 & 12.7 & 1.00 & 0.83 & 9.35 & 7.54 \\
\hline & & 8.5 & 3.6 & 0.30 & 0.25 & 1.23 & 0.98 \\
\hline \multirow[t]{2}{*}{$30 \mathrm{~N}$} & \multirow[t]{2}{*}{$330 \mathrm{E}$} & 158.4 & 24.9 & 3.51 & 2.89 & 31.42 & 23.98 \\
\hline & & 8.5 & 7.1 & 1.57 & 1.30 & 5.55 & 4.05 \\
\hline \multirow[t]{2}{*}{ o } & \multirow[t]{2}{*}{$330 \mathrm{E}$} & 158.4 & 20.3 & 2.49 & 2.05 & 22.81 & 17.91 \\
\hline & & 8.5 & 8.0 & 1.11 & 0.91 & 4.79 & 4.39 \\
\hline \multirow[t]{2}{*}{$30 \mathrm{~S}$} & \multirow[t]{2}{*}{$330 \mathrm{E}$} & 158.4 & 9.5 & 0.65 & 0.53 & 5.38 & 4.60 \\
\hline & & 8.5 & 3.2 & 0.27 & 0.22 & 1.01 & 0.83 \\
\hline \multirow[t]{2}{*}{$30 \mathrm{~S}$} & \multirow[t]{2}{*}{$60 \mathrm{E}$} & 158.4 & 5.3 & 0.31 & 0.25 & 1.83 & 1.68 \\
\hline & & 8.5 & 2.2 & 0.21 & 0.17 & 0.65 & 0.48 \\
\hline \multirow[t]{2}{*}{$75 N$} & \multirow[t]{2}{*}{$160 \mathrm{E}$} & 158.4 & 18.7 & 3.32 & 2.74 & 17.70 & 22.86 \\
\hline & & 8.5 & 6.3 & 2.19 & 1.80 & 6.08 & 4.40 \\
\hline
\end{tabular}

Ionospheric attenuation and emission at nadir during High Solar Activity (HSA) and Low Solar Activity (LSA) over various locations on ocean surface. The ocean surface has salinity $(S)=35 \mathrm{psu}$ and surface temperature $\left(\mathrm{T}_{0}\right)=20^{\circ} \mathrm{C}$. The computation is for JUNE and local time of $6 \mathrm{AM}$. In this table, $\tau$ is the optical depth; $\Delta \mathrm{T}$ is the change in brightness temperature due to ionosphere attenuation; $T \uparrow$ is the upwelling emission from the ionosphere; and $T_{\downarrow}$ is the downwelling after reflection from ocean surface.

TABLE III

IONOSPHERIC ATTENUATION AND EMISSION (NOON)

\begin{tabular}{|c|c|c|c|c|c|c|c|}
\hline \multicolumn{2}{|c|}{ Location } & \multirow[t]{2}{*}{$\mathbf{R z}$} & \multirow{2}{*}{$\begin{array}{c}\text { VTEC } \\
\text { (TECU) }\end{array}$} & \multirow{2}{*}{$\begin{array}{c}\tau \\
\left(10^{-5} \text { Neper }\right)\end{array}$} & \multirow{2}{*}{$\begin{array}{c}\Delta \mathbf{T} \\
(\mathbf{m K})\end{array}$} & \multirow{2}{*}{$\begin{array}{c}\mathbf{T}_{\uparrow} \\
(\mathbf{m K})\end{array}$} & \multirow{2}{*}{$\underset{(\mathbf{m K})}{\mathbf{T}_{\downarrow}}$} \\
\hline Latitude & Longitude & & & & & & \\
\hline \multirow[t]{2}{*}{$30 \mathrm{~N}$} & \multirow[t]{2}{*}{$220 \mathrm{E}$} & 158.4 & 39.8 & 11.43 & 9.42 & 77.34 & 57.46 \\
\hline & & 8.5 & 14.2 & 5.00 & 4.12 & 18.49 & 13.52 \\
\hline \multirow[t]{2}{*}{$\mathbf{0}$} & \multirow[t]{2}{*}{$220 \mathrm{E}$} & 158.4 & 45.0 & 13.42 & 11.06 & 99.21 & 78.06 \\
\hline & & 8.5 & 17.3 & 5.81 & 4.78 & 22.22 & 19.41 \\
\hline \multirow[t]{2}{*}{$30 \mathrm{~S}$} & \multirow[t]{2}{*}{$220 \mathrm{E}$} & 158.4 & 37.9 & 10.22 & 8.42 & 80.89 & 59.12 \\
\hline & & 8.5 & 9.0 & 3.26 & 2.69 & 10.32 & 7.59 \\
\hline \multirow[t]{2}{*}{$30 \mathrm{~N}$} & \multirow[t]{2}{*}{$330 \mathrm{E}$} & 158.4 & 43.5 & 12.37 & 10.20 & 89.77 & 67.04 \\
\hline & & 8.5 & 13.8 & 5.03 & 4.15 & 18.50 & 13.45 \\
\hline \multirow[t]{2}{*}{ 0 } & \multirow[t]{2}{*}{$330 \mathrm{E}$} & 158.4 & 48.3 & 14.47 & 11.92 & 113.48 & 87.74 \\
\hline & & 8.5 & 17.7 & 5.93 & 4.88 & 23.24 & 19.51 \\
\hline \multirow[t]{2}{*}{$30 \mathrm{~S}$} & \multirow[t]{2}{*}{$330 \mathrm{E}$} & 158.4 & 35.7 & 9.98 & 8.22 & 75.06 & 54.73 \\
\hline & & 8.5 & 11.3 & 3.64 & 3.00 & 13.08 & 9.76 \\
\hline \multirow[t]{2}{*}{$30 \mathrm{~S}$} & \multirow[t]{2}{*}{$60 \mathrm{E}$} & 158.4 & 39.8 & 10.68 & 8.80 & 85.87 & 63.13 \\
\hline & & 8.5 & 9.8 & 3.46 & 2.85 & 11.82 & 8.57 \\
\hline \multirow[t]{2}{*}{$75 \mathrm{~N}$} & \multirow[t]{2}{*}{$160 \mathrm{E}$} & 158.4 & 20.1 & 6.11 & 5.034 & 24.57 & 28.29 \\
\hline & & 8.5 & 6.7 & 2.60 & 2.134 & 7.29 & 5.27 \\
\hline
\end{tabular}

Ionospheric attenuation and emission at nadir during High Solar Activity (HSA) and Low Solar Activity (LSA) over various locations on ocean surface. The ocean surface has salinity $(S)=35 \mathrm{psu}$ and surface temperature $\left(\mathrm{T}_{0}\right)=20^{\circ} \mathrm{C}$. The computation is for JUNE and local time of noon. In this table, $\tau$ is the optical depth; $\Delta T$ is the change in brightness temperature due to ionosphere attenuation; $T \uparrow$ is the upwelling emission from the ionosphere; and $T_{\downarrow}$ is the downwelling after reflection from ocean surface.

\section{COMMENTS}

Calculations have been presented here illustrating the effect of Faraday rotation and attenuation/emission from the ionosphere on passive microwave remote sensing at L-band (1.4 $\mathrm{GHz}$ ). The motivation for this work is current interest in remote sensing of ocean salinity from space. To put the effects of the ionosphere into context, the change of brightness temperature with salinity is about $0.5 \mathrm{~K} / \mathrm{psu}$. It is clear from Figs. 2 and
3 (error due to Faraday rotation) and Tables II and III (error due to attenuation and emission) that corrections for these phenomena will have to be made to achieve salinity retrievals accurate to $0.1-0.2$ psu.

The data also indicate some obvious choices for remote sensing. Clearly an optimum choice as far as minimizing errors is 6 am local time and as close to a minimum of solar activity as possible. Local time of $6 \mathrm{am}$ is near the minimum in the daily cycle of the ionosphere, (Fig. 7 is an example of the 

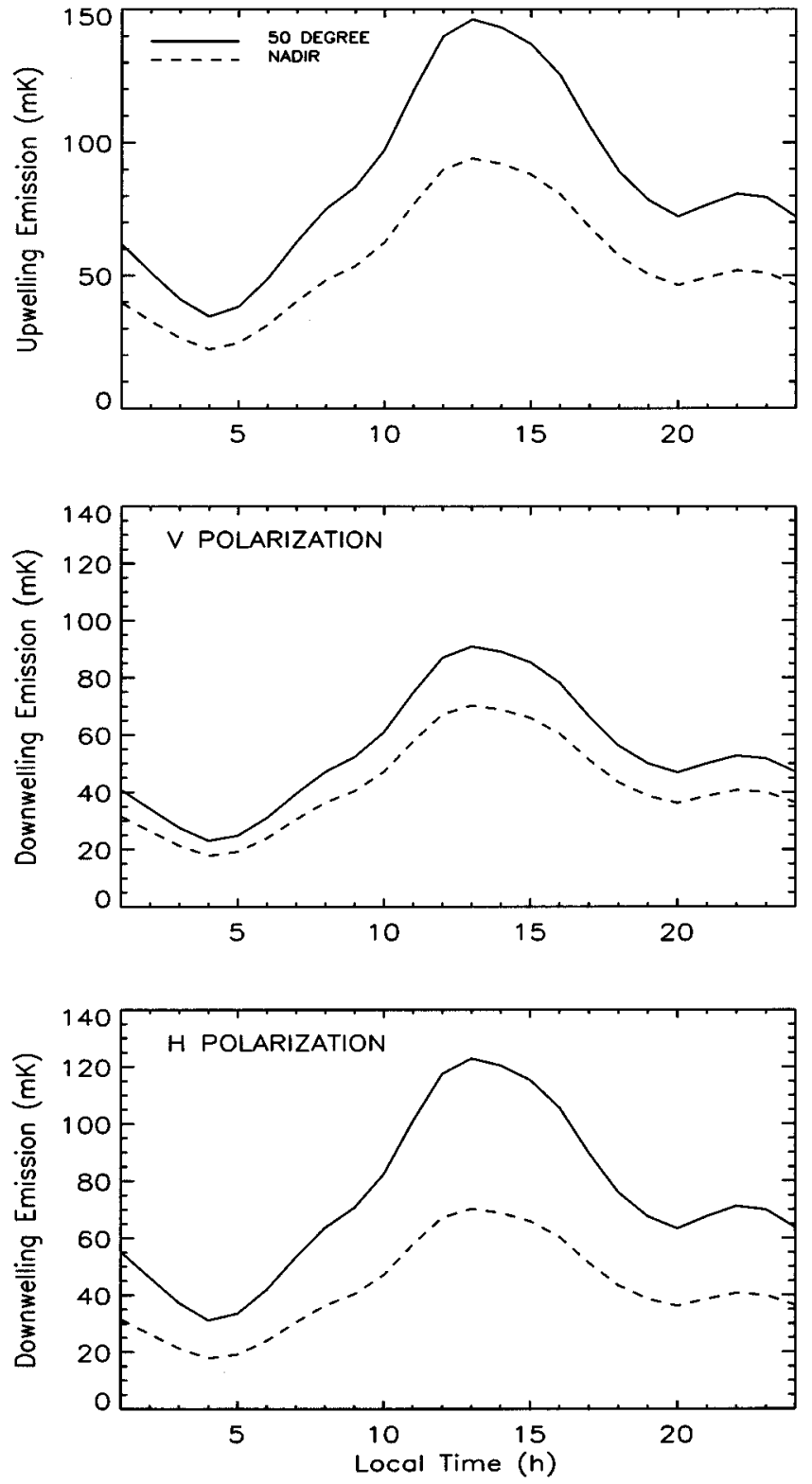

Fig. 7. Diurnal variation of upwelling (top) and downwelling emissions (vertical polarization, middle; horizontal polarization, bottom). The calculations are at $30 \mathrm{~N}, 330 \mathrm{E}$ during high solar activity (June 1989). The surface is ocean with $S=35$ psu and $T_{0}=20^{\circ} \mathrm{C}$.

diurnal variation). Remote sensing from a sun-synchronous orbit with an equatorial crossing time of $6 \mathrm{am} / 6 \mathrm{pm}$ would provide observations near this minimum. Fig. 1 and Tables I-III illustrate the dependence on solar activity. For a fixed local time and location, Faraday rotation and emission/absorption increase roughly linearly with the solar activity (IG) index, Rz.

The studies presented here use the IRI-95 and are therefore representative of climatalogical data for the ionosphere. The
IRI-95 model [17] is a good representation of mean characteristics of the ionosphere but is not a particularly good predictor of current (instantaneous) behavior [24], [25]. It may be possible to improve its ability to predict current behavior given input of local, measured parameters [26], [27]. However, without such input corrections for Faraday rotation and emission will likely have to be based on other models or techniques. (One possibility is to measure the third Stokes parameter [28].)

Attenuation is proportional to $\nu_{z}$ as in (7) which follows from the Appleton-Hartree equation and simplifications for L-band. This is a "cold" plasma approximation. In the present study, the collision frequency is taken as $\nu_{z}=\nu_{\text {eff }}$ (see (9)-(10)). It has been suggested that, when $\nu \gg \nu_{\text {eff }}$, as is the case at L-band, a better approximation is to use $\nu_{z}=1.333 \nu_{\text {eff }}$ [29]. Hence, it is likely that the values for emission and loss given here are underestimated. Also, the results presented here employ approximations that are reasonable at low and middle latitudes. Near the poles, additional care must be taken in the calculation of attenuation [30].

\section{APPENDIX A \\ REFRACTIVE INDEX AT L BAND}

The effective refractive index for electromagnetic wave propagation in the ionosphere is given by the Appleton-Hartree equation [31], [32] (A1), shown at the bottom of the page, where $\nu$ is frequency and $\theta_{B}$ is the angle between the direction of propagation and the geomagnetic field and where

$$
\hat{\nu}_{p}=\frac{\nu_{p}}{\nu}, \hat{\nu}_{B}=\frac{\nu_{B}}{\nu}, \hat{\nu}_{z}=\frac{\nu_{z}}{2 \pi \nu} .
$$

In these expressions, $\nu_{p}$ is the plasma frequency $(\mathrm{Hz})$

$$
\begin{aligned}
\nu_{p} & =\sqrt{\frac{N e^{2}}{4 \pi^{2} \epsilon_{o} m}} \\
& \approx 9 \sqrt{N}
\end{aligned}
$$

where $N$ is the number of electrons per $\mathrm{m}^{3}$ and $\nu_{B}$ is the electron gyro frequency $(\mathrm{Hz})$

$$
\nu_{B}=\frac{e B}{2 \pi m} .
$$

At L-band $(1.4 \mathrm{GHz})$ the frequency is sufficiently larger than the maximum plasma frequency and the gyro frequency that simplifying assumptions can be made to the classical magneto-ionic theory. In particular, the terms in (A1) proportional to $\operatorname{Sin}\left(\theta_{B}\right)$ can be neglected as long as $\theta_{B} \leq 89^{\circ}$. This is called the quasilongitudinal approximations, and one obtains [14]

$$
n_{ \pm}^{2} \cong 1-\frac{\hat{\nu}_{p}^{2}}{1-j \hat{\nu}_{z} \pm \hat{\nu}_{B} \operatorname{Cos} \theta_{B}} .
$$

$$
n_{ \pm}^{2}=1-\frac{\hat{\nu}_{p}^{2}}{1-j \hat{\nu}_{z}-\left[\frac{\hat{\nu}_{B}^{2} \operatorname{Sin}^{2} \theta_{B}}{2\left(1-\hat{\nu}_{p}^{2}-j \hat{\nu}_{z}\right)}\right] \pm\left[\frac{\hat{\nu}_{B}^{4} \operatorname{Sin}^{4} \theta_{B}}{4\left(1-\hat{\nu}_{p}^{2}-j \hat{\nu}_{z}\right)^{2}}+\hat{\nu}_{B}^{2} \operatorname{Cos}^{2} \theta_{B}\right]^{1 / 2}}
$$


Rationalizing the denominator and only keeping terms of lowest order in $\nu_{p} / \nu$ and $\nu_{B} / \nu$ and $\nu_{z} / \nu$ in the numerator, one may write this as

$$
n_{ \pm}^{2} \approx 1-\hat{\nu}_{p}^{2}\left[1 \mp \hat{\nu}_{B} \operatorname{Cos} \theta_{B}\right]-j \hat{\nu}_{p}^{2} \hat{\nu}_{z}
$$

Finally, using the definitions

$$
\begin{aligned}
\mu_{0} & =1-\frac{1}{2} \hat{\nu}_{p}^{2} \\
\Delta & =\frac{1}{2} \hat{\nu}_{p}^{2} \hat{\nu}_{B} \operatorname{Cos} \theta_{B} \\
\chi_{0} & =\frac{1}{2} \hat{\nu}_{p}^{2} \hat{\nu}_{z} \\
\alpha & =1+\frac{1}{2} \hat{\nu}_{p}^{2}
\end{aligned}
$$

and taking the square root of (A5), one obtains

$$
n_{ \pm}=\left(\mu_{0} \pm \Delta\right)+j \chi_{0}(-\alpha \pm \Delta) \text {. }
$$

\section{APPENDIX B}

\section{Propagation of a Plane WaVE in the IONOSPHERE}

Assume a plane (flat) layered ionosphere divided into many layers sufficiently thin that the index of refraction is constant within each layer. That is, neglect curvature; assume that the only variations are vertical and that the vertical variations are slowly varying. We approximate the solution for propagation in this model ionosphere by solving for plane-wave propagation within each layer assuming constant index of refraction $n$ and later summing the solutions over all the layers.

To begin, consider a linearly polarized wave propagating in the $z$-direction within the $i$ th layer. It has the following form:

$$
E_{i}(z)=E_{\mathrm{xi}} x \exp \left[-j k_{o} n_{i} z\right]
$$

It is possible to write this linearly polarized wave as the sum of the two circularly polarized waves. Doing so and recognizing that in the ionosphere the two modes propagate with different velocities (i.e., index of refraction, $n_{ \pm}$, in (A7)), one obtains

$$
\begin{aligned}
E_{i}(z)=\left(\frac{1}{2}\right) E_{\mathrm{xi}}(x+j y) \exp \left[-j k_{o} n_{+} z\right] \\
+\left(\frac{1}{2}\right) E_{\mathrm{xi}}(x-j y) \exp \left[-j k_{o} n_{-} z\right]
\end{aligned}
$$

where $x$ and $y$ denote unit vectors along the $x$ and $y$ axes, respectively, and the subscript " $i$ " on $n_{ \pm}$has been dropped to make the notation easier. Substituting for $n_{ \pm}$from (A7), one obtains

$$
\begin{aligned}
E_{i}(z)= & \exp \left(-j \theta_{o} z\right) \exp (-\beta z) \\
& \cdot\left\{\left(\frac{1}{2}\right) E_{\mathrm{xi}}(x+j y) \exp [-j \Omega z] \exp [\delta z]\right. \\
& \left.+\left(\frac{1}{2}\right) E_{\mathrm{xi}}(x-j y) \exp [+j \Omega z] \exp [-\delta z]\right\}
\end{aligned}
$$

where

$$
\begin{aligned}
k_{o} & =\frac{2 \pi \nu}{c} \\
\theta_{0} & =k_{o} \mu_{o} \\
\beta & =k_{o} \chi_{o} \alpha \\
\Omega & =k_{o} \Delta \\
\delta & =k_{o} \Delta \chi_{0} .
\end{aligned}
$$

Because the two modes propagate with different phase velocity, the polarization vector changes and because the index of refraction $n_{ \pm}$is complex, there is attenuation. For example, in the special case $\delta=0$, both modes in (B3) are attenuated by the factor $\exp (-\beta z)$ and the polarization vector rotates through an angle $\Omega z$. The latter is Faraday rotation. The wave emerges linearly polarized but with reduced amplitude and with the direction of the polarization vector changed. When $\delta \neq 0$ the two modes do not entirely add in phase and the wave has a slight elliptically polarized component. At L-band $\delta$ is very small (Table I) and will be neglected in this paper. The two dominant effects at L-band are Faraday rotation (determined by $\Omega$ ) and attenuation (determined by $\beta$ ).

To obtain an expression for the complete path, one needs to sum over all the layers. Assuming that the changes are sufficiently gradual that we can neglect reflections as the boundaries and that the layers are sufficiently thin and numerous that sums are approximated by integrals, one obtains

$$
\begin{aligned}
E(z)= & \sum_{i=0}^{h} E_{i}(z) \\
= & \exp \left(-j \theta_{0} z\right) \exp (-\tau(h)) \\
& \cdot\left\{\left(\frac{1}{2}\right) E_{x}(x+j y) \exp \left[-j \Omega_{F}(h)\right]\right. \\
& \left.+\left(\frac{1}{2}\right) E_{x}(x-j y) \exp \left[+j \Omega_{F}(h)\right]\right\}
\end{aligned}
$$

where

$$
\begin{aligned}
\tau(h) & =\int_{0}^{h} \beta(z) \mathrm{d} z \\
\Omega_{F}(h) & =\int_{0}^{h} \Omega(z) \mathrm{d} z .
\end{aligned}
$$

\section{ACKNOWLEDGMENT}

The authors wish to thank the Dr. D. Bilitza (National Space Science Data Center, Greenbelt) for providing atmosphere and ionosphere models.

\section{REFERENCES}

[1] R. Murtugudde and A. Busalacchi, "Simulation of the tropical oceans with an ocean GCM coupled to an atmospheric mixed layer model," $J$. Climate, vol. 9, pp. 1795-1815, 1998.

[2] G. Lagerloef, C. Swift, and D. M. Le Vine, "Sea surface salinity: The next remote sensing challenge," Oceanography, vol. 8, pp. 44-50, 1995.

[3] R. W. Schmitt, "The ocean freshwater cycle," in JSC Ocean Observing Development Panel. $\quad$ College Station, TX: Texas A\&M Univ., 1994, p. 40.

[4] D. M. Le Vine, J. B. Zaitzeff, E. J. D’Sa, J. L. Miller, C. T. Swift, and M. Goodberlet, "Sea surface salinity: Toward and operational remote sensing system," in Satellites, Oceanography and Society, D. Halpern, Ed. Amsterdam, The Netherlands: Elsevier, 2000, pp. 321-335. 
[5] H.-J. C. Blume, B. M. Kendall, and J. C. Fedors, "Measurements of ocean temperature and salinity via microwave radiometry," Bound. Layer Met., vol. 13, pp. 295-308, 1978.

[6] L. A. Klein and C. T. Swift, "An improved model for the dielectric constant of sea water at microwave frequencies," IEEE Trans. Antennas Propagat., vol. AP-25, pp. 104-111, Jan. 1977.

[7] C. T. Swift and R. E. McIntosh, "Considerations for microwave remote sensing of ocean-surface salinity," IEEE Trans. Geosci. Remote Sensing, vol. GE-21, pp. 480-491, 1983.

[8] R. M. Lerner and J. P. Hollinger, "Analysis of $1.4 \mathrm{GHz}$ radiometric measurements from Skylab,” Remote Sens. Environ., vol. 6, pp. 251-269, 1977.

[9] J. L. Miller, M. A. Goodberlet, and J. B. Zaitzeff, "Airborne salinity mapper makes debut in coastal zone," EOS, Trans. AGU, vol. 79, no. 173, pp. 176-177, 1998.

[10] D. M. Le Vine, M. Kao, R. Garvine, and T. Sanders, "Remote sensing of ocean salinity: Results from the Delaware coastal current experiment," J. Tech., vol. 15, pp. 1478-1484, 1998.

[11] E. L. Lewis, "The practical salinity scale 1978 and its antecedents," IEEE J. Oceanic Eng., vol. OE-5, pp. 3-8, 1980.

[12] P. E. O'Neill, A. Hsu, T. Jackson, and C. Swift, "Ground-based microwave radiometer measurements during the Southern Great Plains '97 Experiment," in Proc. IGARSS-98, Seattle, WA, July 1998, pp. $1843-1845$

[13] T. J. Schmugge, P. E. O’Neill, and J. Wang, "Passive microwave soil moisture research," IEEE Trans. Geosci. Remote Sensing, vol. GE-24, p. 12,1986

[14] A. R. Thompson, J. M. Moran, and G. W. Swenson, Interferometry and Synthesis in Radio Astronomy. New York: Wiley, 1986.

[15] G. H. Millman, "The geometry of earth's magnetic field at ionospheric heights," J. Geophys. Res., vol. 64, no. 7, p. 717, 1959.

[16] D. M. Le Vine and S. Abraham, "Faraday rotation and passive microwave remote sensing of soil moisture from space," in Microw. Radiomet. Remote Sens. Earth's Surf. Atmosphere, P. Pampaloni and S. Paloscia, Eds: VSP, 2000, pp. 89-96.

[17] D. Bilitza, "International Reference Ionosphere-Status 1995/1996," Adv. Space Res., vol. 20, no. 9, pp. 1751-1754, 1997.

[18] C. E. Barton, "International geomagnetic reference field: The seventh generation," J. Geomagn. Geoelectr., vol. 49, pp. 123-148, 1997.

[19] S. Abraham and D. M. Le Vine, "Evaluation of IRI-95 to correct errors caused by Faraday rotation in passive microwave remote sensing from space," Adv. Space Res., vol. 27, no. 1, pp. 153-156, 2001.

[20] H. Rishbeth and O. K. Garriott, Introduction to Ionospheric Physics. New York: Academic, 1969.

[21] A. E. Hedin, "Extension of the MSIS thermospheric model into the middle and lower atmosphere," J. Geophys. Res., vol. 96, p. 1159, 1991.

[22] H.-J.C. Blume and B. M. Kendall, "Passive microwave measurements of temperature and salinity in coastal zones," IEEE Trans. Geosci. Remote Sensing, vol. GE-20, pp. 394-404, 1982.

[23] G. S. E. Lagerloef, "Final Report of the First Workshop Salinity Sea Ice Working Group (SSIWG),", http://www.esr.org, 1998.

[24] A. J. Preble, D. N. Anderson, B. G. Fejer, and P. H. Doherty, "Comparison between calculated and observed $\mathrm{F}$ region electron density profiles at Jicamarca, Peru," Radio Sci., vol. 4, pp. 857-866, 1994.

[25] W. S. Schreiner, R. E. Markin, and G. H. Born, "Correction of single frequency altimeter measurements for ionosphere delay," IEEE Trans. Geosci. Remote Sensing, vol. 35, pp. 271-277, Feb. 1997.

[26] A. Komjathy, K. Gold, and G. Born, "A comparison of updating PRISM and IRI-95 using JPL-derived GIM's for single frequency satellite altimetry," in Ionospheric Determination and Specification for Ocean Altimetry and GPS Surface Reflection Workshop. Pasadena, CA: Jet Propulsion Lab., 1997.

[27] A. Komjathy, R. B. Langley, and D. Bilitza, "Ingesting GPS-derived TEC data into the International Reference Ionosphere for single frequency radar altimeter ionosphere delay corrections," Adv. Space Res., vol. 22 , no. 6, pp. 793-801, 1998.
[28] S. H. Yueh, "Estimates of Faraday rotation with passive microwave polarimetry for microwave remote sensing of earth surfaces," IEEE Trans. Geosci. Remote Sensing, vol. 38, pp. 2434-2438, Sept. 2000.

[29] J. V. Evans and T. Hagfors, Radar Astronomy. New York: McGrawHill, 1968.

[30] "Propagation in Ionized Media: Recommendations and Reports of the CCIR," CCIR, Rep. 263-5, vol. VI, 1982.

[31] J. A. Ratcliffe, Magneto Ionic Theory and its Applications to the Ionosphere. Cambridge, U.K.: Cambridge Univ. Press, 1959.

[32] N. C. Gerson, "General absorption theory," in Radio Wave Absorption in the Ionosphere, N. C. Gerson, Ed. New York: Pergamon, 1962, ch. 1.

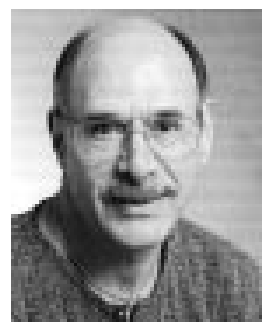

David M. Le Vine (M'70-SM'79-F'95) received the B.S. and M.S. degrees in electrical engineering, the M.S. degree in physics, and the Ph.D. degree in electrical engineering from the University of Michigan, Ann Arbor.

He has been employed as an Electronics Engineer at the Harry Diamond Laboratory, Department of the Army, and as a Research Engineer at the Radiation Laboratory, University of Michigan. After leaving the University of Michigan, he became Assistant Professor in the Department of Electrical Engineering at the University of Maryland, College Park. In 1973, he joined NASA's Goddard Space Flight Center, Greenbelt, MD, where he is currently a member of the Microwave Sensors Branch. His current research has focused on the development of techniques for microwave remote sensing of the environment from space.

Dr. Le Vine is a member of the International Union of Radio Science (URSI, Commisions B, E and F) and the American Geophysical Union. Within the IEEE he is affiliated with the Antennas and Propagation Society and the Geoscience and Remote Sensing Society. He was president of the local (Washington, DC) section of the Antennas and Propagation Society and has been active in engineering accreditation. He is currently a member of the IEEE Committee on Engineering Accreditation Activities (CEAA) and is one of the IEEE representatives on the Engineering Accreditation Commission (EAC) of ABET. He is a member of Eta Kappa Nu, Tau Beta Pi, and Phi Kappa Phi. He was a University of Michigan Fellow and NASA/ASEE Faculty Fellow and is the recipient of several service awards from the Goddard Space Flight Center.

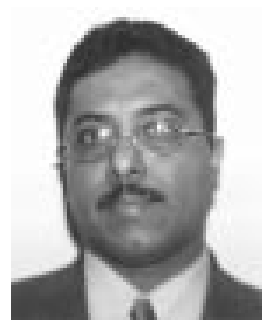

Saji Abraham (M'01) received the B.Sc. degree in physics from Kerala University, India, and the M.Sc. degree in space physics from Andhra University, India, and the Ph.D. degree in space physics from the University of Delhi, India.

$\mathrm{He}$ has been supporting NASA projects since 1997 and is currently employed with Science System and Applications, Inc. (SSAI), Greenbelt, MD. His current research includes developing forward models to simulate brightness temperature at microwaves for space-born sensors and sea surface salinity retrieval algorithms. He has worked in research areas related to ionosphere radio wave propagation techniques and has published scientific articles on lower ionosphere dynamics and its coupling with the lower atmosphere through planetary waves and Quasi-biennial Oscillations (QBO).

Dr. Abraham is a member of the American Geophyical Union and the IEEE Geoscience and Remote Sensing Society. 